\title{
Influence of tides and gravity waves on layering processes in the polar summer mesopause region
}

\author{
P. Hoffmann, M. Rapp, J. Fiedler, and R. Latteck \\ Leibniz-Institute of Atmospheric Physics, Kühlungsborn, Germany \\ Received: 7 November 2007 - Revised: 3 July 2008 - Accepted: 7 November 2008 - Published: 9 December 2008
}

\begin{abstract}
Polar Mesosphere Summer Echoes (PMSE) have been studied at Andenes ( $\left.69^{\circ} \mathrm{N}, 16^{\circ} \mathrm{E}\right)$, Norway, using VHF radar observations since 1994 . One remarkable feature of these observations is the fact that during $50 \%$ of the time, the radar echoes occur in the form of two or more distinct layers. In the case of multiple PMSE layers, statistical analysis shows that the lower layer occurs at a mean height of $\sim 83.4 \mathrm{~km}$, which is almost identical to the mean height of noctilucent clouds (NLC) derived from observation with the ALOMAR Rayleigh/Mie/Raman lidar at the same site. To investigate the layering processes microphysical model simulations under the influence of tidal and gravity waves were performed. In the presence of long period gravity waves, these model investigations predict an enhanced formation of multiple PMSE layer structures, where the lower layer is a consequence of the occurrence of the largest particles at the bottom of the ice cloud. This explains the coincidence of the lowermost PMSE layers and NLC. During periods with enhanced amplitudes of the semidiurnal tide, the observed NLC and PMSE show pronounced tidal structures comparable to the results of corresponding microphysical simulations. At periods with short period gravity waves there is a tendency for a decreasing occurrence of NLC and for variable weak PMSE structures.
\end{abstract}

Keywords. Atmospheric composition and structure (Aerosols and particles; Middle atmosphere - composition and chemistry) - Meteorology and atmospheric dynamics (Middle atmosphere dynamics; Waves and tides)

\section{Introduction}

During summer, the thermal state of the polar mesosphere is characterized by the lowest temperatures of the Earth's at-

Correspondence to: P. Hoffmann

(hoffmann@iap-kborn.de) mosphere allowing the formation of ice clouds, known as noctilucent clouds (NLC). Starting from the initial observations by Hansen et al. (1989); NLC have been routinely observed applying ground based lidars since 1997 (see Fiedler et al., 2003). These ice particles also give rise to very strong radar echoes first detected by Czechowsky et al. (1979) and Ecklund and Balsley (1981) and which are referred to as polar mesosphere summer echoes (PMSE). The current understanding of this phenomenon has been summarized by Rapp and Lübken (2004).

PMSE have been observed at different stations, among others at Andenes $\left(69^{\circ} \mathrm{N}, 16^{\circ} \mathrm{E}\right)$ (Bremer et al., 2003), at Tromsoe $\left(69^{\circ} \mathrm{N}, 19^{\circ} \mathrm{E}\right)$ (Röttger et al., 1988), at Kiruna $\left(68^{\circ} \mathrm{N}, 21^{\circ} \mathrm{E}\right)$ (Kirkwood et al., 1998), at Svalbard $\left(78^{\circ} \mathrm{N}\right.$, $16^{\circ} \mathrm{E}$ ) (Hall and Röttger, 2001), and also in the Southern Hemisphere at Davis $\left(69^{\circ} \mathrm{S}, 78^{\circ} \mathrm{E}\right)$ (Morris et al., 2004, 2007), at Halley $\left(76^{\circ} \mathrm{S}, 27^{\circ} \mathrm{W}\right)$ (Jarvis et al., 2005), and at Wasa $\left(73^{\circ} \mathrm{S}, 13^{\circ} \mathrm{W}\right)$ (Kirkwood et al., 2007). Latteck et al. (2007) have found that PMSE in the Southern Hemisphere occur with a smaller reflectivity than those in the Northern Hemisphere. One remarkable feature of all PMSE is the fact that the radar echoes often occur in the form of two or more distinct layers (Hoffmann et al., 2005) and they show clear wavelike structures. Typical PMSE with a double layer structure are shown in Fig. 1.

One of the open questions regarding mesospheric clouds is related to the influence of tidal and gravity waves on the layering processes leading to NLC and PMSE. Previous studies have been directed to the contribution of gravity waves, the general thermal structure, and Kelvin-Helmholtz-instabilities on PMSE (Röttger, 1994; Klostermeyer, 1997; Hill et al., 1999). Tidal variations of brightness and centroid altitudes of NLC have initially been detected by von Zahn et al. (1998) and were recently summarized by Fiedler et al. (2005). The association of PMSE with different tidal modes has been as first detected by Williams et al. (1995). Particularly, the influence of semidiurnal tides on the variation of PMSE has been

Published by Copernicus Publications on behalf of the European Geosciences Union. 


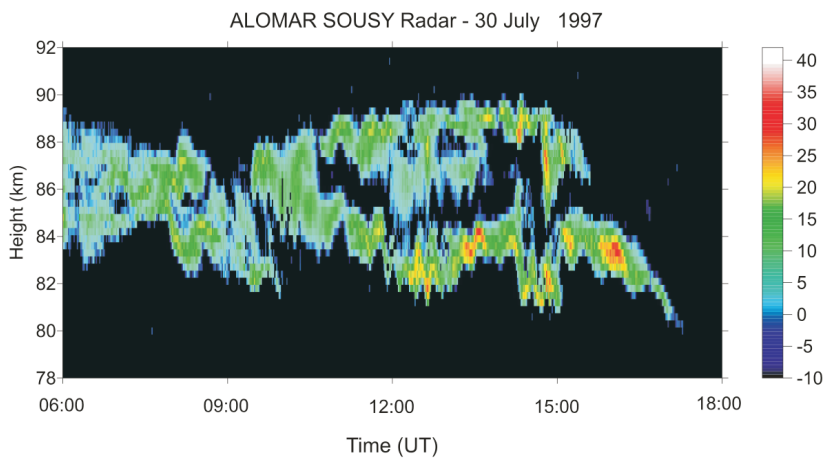

Fig. 1. Signal-to-noise ratio in $\mathrm{dB}$ of the backscattered echo power, derived from measurements with the VHF radar at Andenes with the vertically directed beam on 30 July 1997.

studied by Barabash et al. (1998), Hoffmann et al. (1999), and recently by Morris et al. (2006).

Possible reasons for the formation of double layer PMSE structures have been discussed by Röttger (2003) based on earlier work by Röttger (1981), where the relation between waves and thin scattering layers in the stratosphere was studied. Based on microphysical model simulations by Rapp et al. (2003), Hoffmann et al. (2005) found an enhanced formation of multiple PMSE layer structures in the presence of long period gravity waves.

In the current paper we are studying the influence both of short and long period gravity waves and of tidal waves on both PMSE and NLC. For these purposes, microphysical model simulations of the generation and growth of mesospheric charged particles (Rapp et al., 2003) have been carried out to consider the impact of idealized wave disturbances with different scales on the microphysics of ice particles. Finally, the results of these simulations are tested using case studies with simultaneous wind measurements and common volume PMSE and NLC observations either influenced by dominating tides in comparison with a reduced activity of short period waves or by enhanced activity of short period waves but with relatively weak tidal wave amplitudes.

\section{Data base and model simulations}

\subsection{Observations}

PMSE observations are available from 1994-1997 using the ALOMAR SOUSY VHF radar (Arctic Lidar Observatory for Middle Atmosphere Research/SOUnding SYstem) and since 1999 with the ALWIN VHF radar (ALOMAR wind radar) at Andenes $\left(69^{\circ} \mathrm{N}, 16^{\circ} \mathrm{E}\right)$. A detailed discussion of these observations is given by Bremer et al. (2003). For our investigation we are using data with a resolution of $300 \mathrm{~m}$ in height and about $5 \mathrm{~min}$ in time obtained during the core PMSE seasons (June and July). Estimates of gravity and tidal wave param-

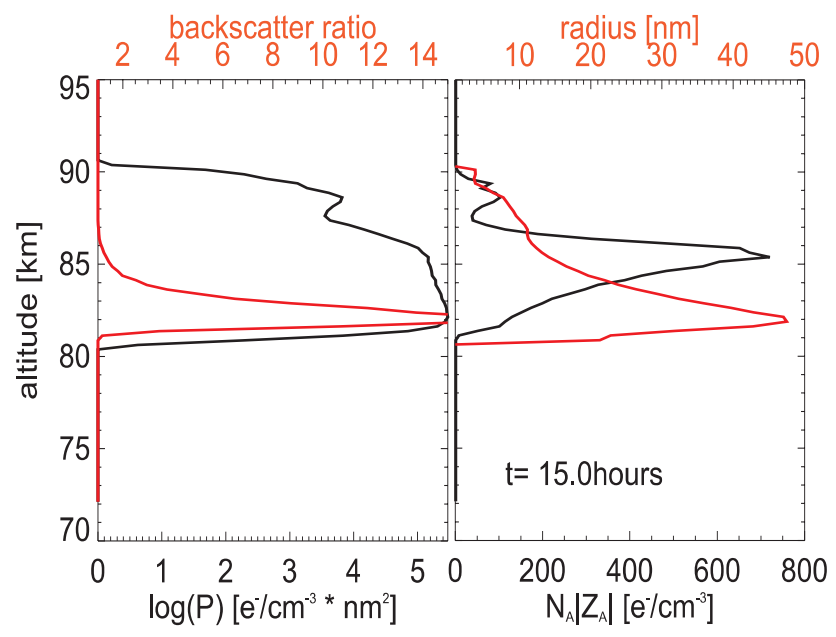

Fig. 2. Model results of the proxy $P$ (black,left), the calculated backscatter ratio that would be seen by a lidar operating at a wavelength of $532 \mathrm{~nm}$ (red, left), the charged particle number density (black, right) and the aerosol particle radius (red, right). This figure is reproduced from Rapp et al. (2003), copyright by the American Geophysical Union.

eters are partly based on case studies of wind measurements with the VHF radar during the presence of PMSE but mainly on measurements with the Andenes MF radar. This radar continuously provides horizontal winds at altitudes between $\sim 70 \mathrm{~km}$ and $94 \mathrm{~km}$ since 1998 using the full correlation analysis method. More details are given in Singer et al. (1997). Wind values are derived with a resolution in height of $2 \mathrm{~km}$ and in time of $3 \mathrm{~min}$. Routinely, the data are averaged independently for each adjacent one hour period and altitude. Prevailing winds, diurnal, and semidiurnal tides are obtained from least square fits of 4-day composite days shifted continuously by one day (e.g. Singer et al., 2005). The gravity wave kinetic energy is estimated from MF radar winds by removing the mean winds and tidal components and applying (Serafimovich et al., 2005) the summarized scale-averaged wavelet analysis (Torrence and Compo, 1998). For the analysis of short period gravity waves the data have been averaged only over $20 \mathrm{~min}$ instead of the regularly used hourly averaged wind values. Isolated data gaps have been substituted by interpolated values.

The ALOMAR Rayleigh/Mie/Raman (RMR) lidar near Andenes operates on a routine basis to measure air density profiles and aerosol particles in the Artic middle atmosphere during day and night (von Zahn et al., 2000). During the summer months, the observation of NLC is one of the major tasks of this lidar. NLC are characterized by their volume backscatter coefficient and by their centroid altitudes (see Fiedler et al., 2003; Baumgarten and Fiedler, 2008, for more details). 


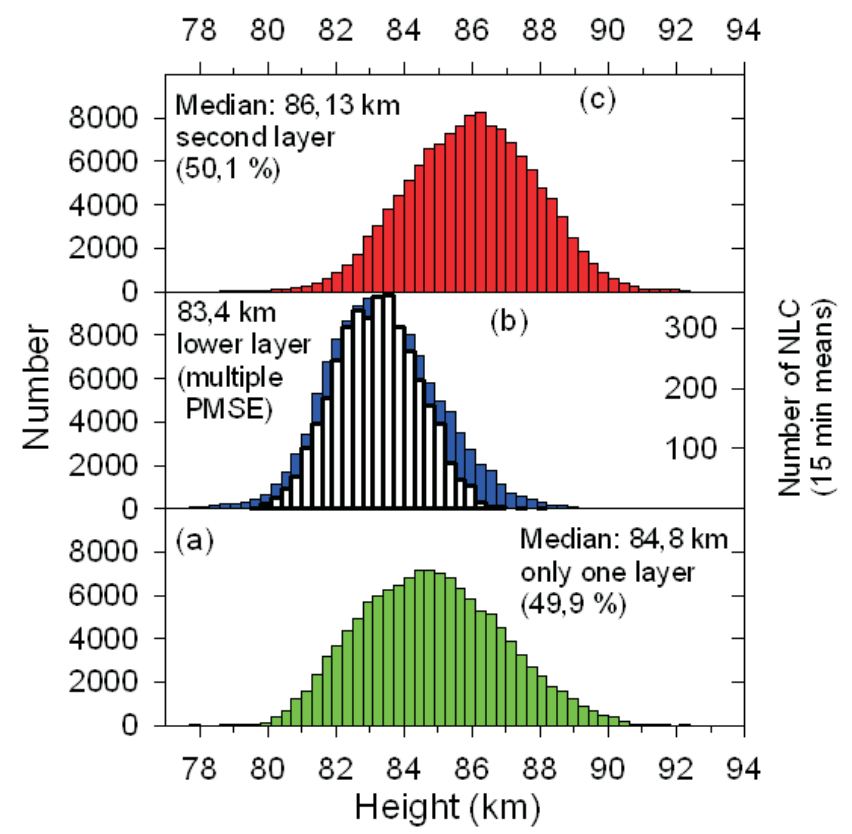

Fig. 3. Histogram of the preferred centroid heights of PMSE and NLC (1997-2004): (a) for PMSE with only one layer; (b) for the lower layer of PMSE in the case of multiple PMSE layer structures (blue) together with the centroid heights of NLC (white); and (c) for the second layer in the case of multiple PMSE layer structures.

\subsection{Model simulations}

Guided by the knowledge on the physical origin of PMSE (Rapp and Lübken, 2004) and earlier observations of gravity wave - ice layer interactions (Rapp et al., 2002), Rapp et al. (2003) developed an empirical proxy for PMSE that can be realized with combined models of ice particle microphysics and aerosol charging. In this framework, the radar reflectivity of the PMSE signal is assumed to be proportional to the product of the charged aerosol number density and the squared radius of the aerosols. Under dynamically quiet conditions, this proxy reproduces the main features of PMSE and also NLC at the lower edge of the PMSE very well as shown in Fig. 2, where profiles of the proxy and the lidar backscatter ratio, the charge number density and the ice particle radius at an arbitrarily selected time during a model simulation are presented. To investigate the influence both of short and long period gravity waves and of tidal waves on both PMSE and NLC, model simulations have been carried out where the winds and temperatures have been disturbed by single idealized waves using parameter based on realistic observed data (more details are given in Rapp et al., 2002).

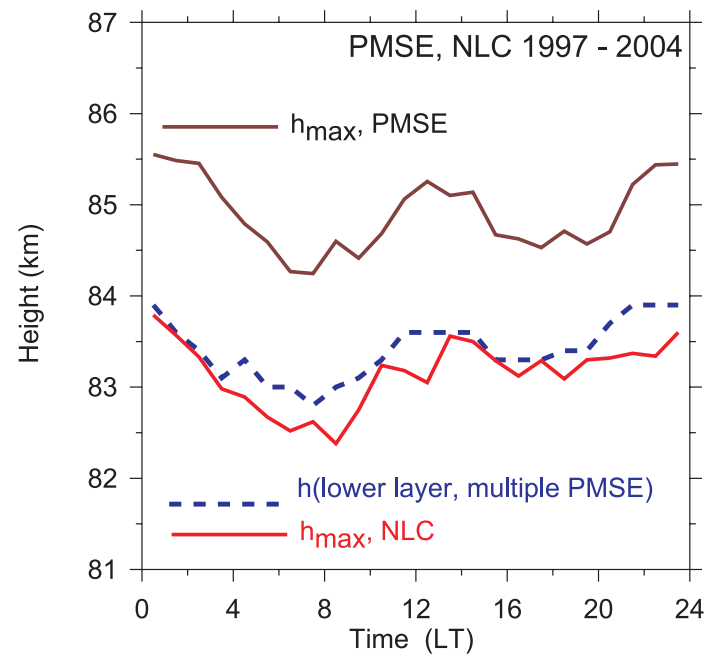

Fig. 4. Diurnal variation of the lower layer in the case of multiple PMSE layers (blue line) in comparison with the diurnal variations of all PMSE (black line) and NLC (red line).

\section{Results and discussions}

\subsection{Multiple PMSE layer and their relation to NLC}

PMSE layer ranges are identified by an SNR-threshold of $5 \mathrm{~dB}$ and by the detection of a relative minimum of $10 \mathrm{~dB}$ below the corresponding maxima (Hoffmann et al., 2005). Then for each single range the corresponding peak height $h_{\text {max }}$ has been selected by finding the maximum. Applying this procedure to the observations from 1997-2004, the histogram of the centroid heights is shown in Fig. 3. According to that, PMSE with two or more layers occur with a rate of about 50\%. The height distribution shows a mean height of $84.8 \mathrm{~km}$ for single PMSE layers, whereas in the case of multiple PMSE layers, the lower layer occurs at a mean height of $\sim 83.4 \mathrm{~km}$ and the layer located above at about $86.1 \mathrm{~km}$. Note that the lower layer of multiple PMSE layers is in surprisingly good agreement with the mean centroid height of NLC (Fig. 3b), and corresponds to the results of the microphysical model simulation, as shown in the left part of Fig. 2. The strong correlation between NLC and PMSE is also demonstrated in Fig. 4 by the mean diurnal variation of the PMSE and NLC altitudes derived from all measurements and confirms first results by von Zahn and Bremer (1999) which were based on a much shorter data set. Note, that the diurnal variation of the altitude of the lower multiple PMSE layer represented by the blue line, is nearly the same as the NLC height variations. Thus we assume that simultaneously observed PMSE and NLC layers with a coincidence of their lower ledges, denoted as "Type 1" in von Zahn and Bremer (1999), are mainly connected with the occurrence of multiple PMSE layers. 

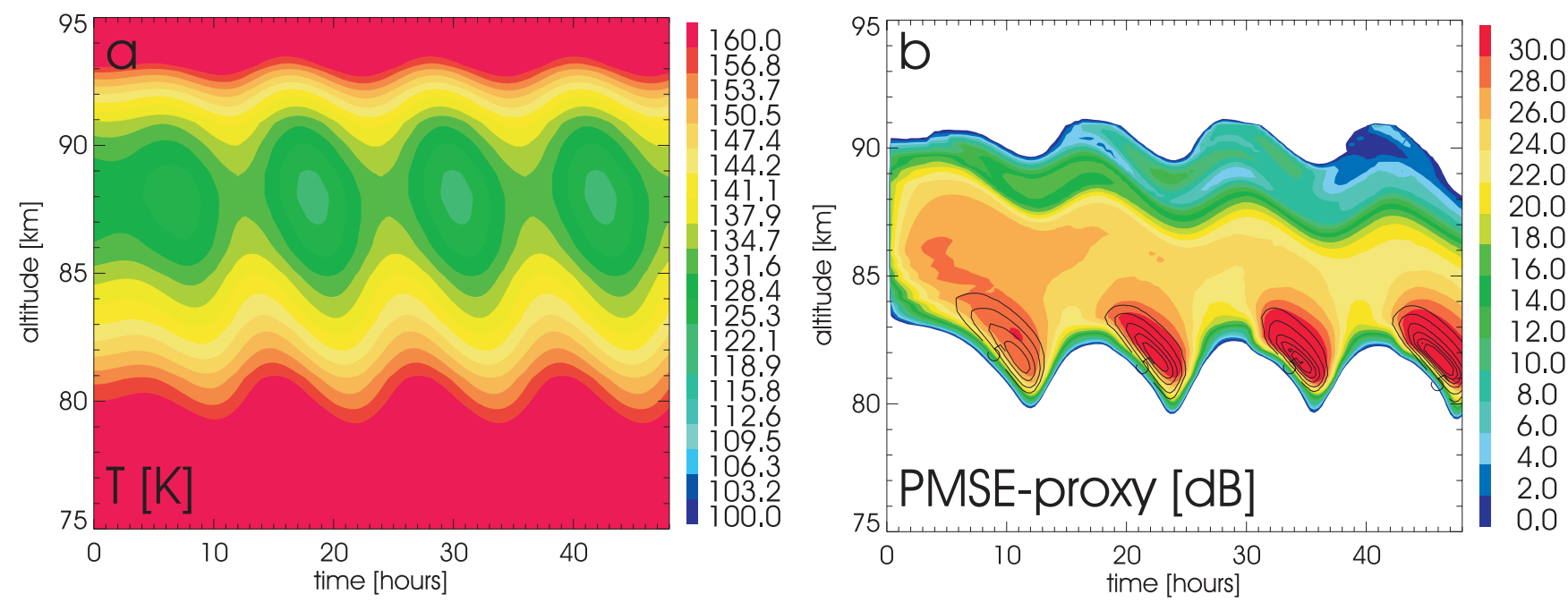

Fig. 5. Model results: (a) Temperature variations under the influence of a semidiurnal tidal wave; (b) resulting PMSE strengths (coloured) and lidar back scatter ratio at $532 \mathrm{~nm}$ (black lines).
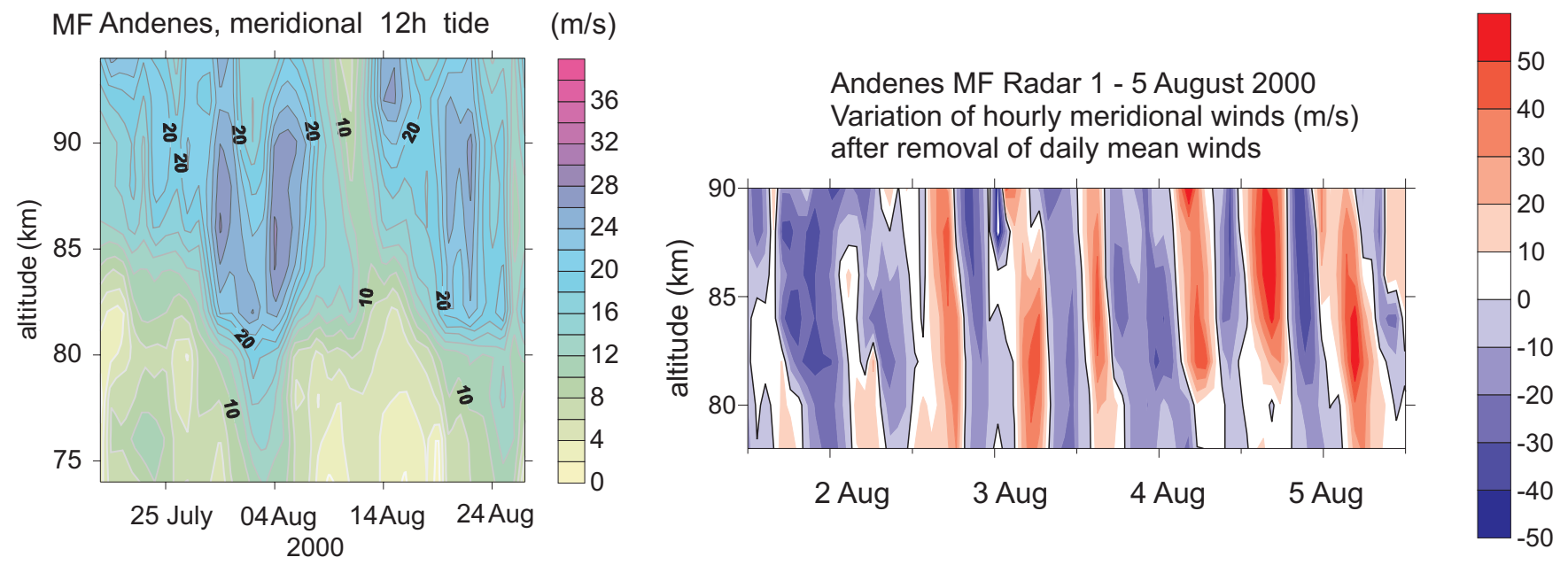

Fig. 6. Observational results: (left) Amplitude of the semidiurnal tide derived from the Andenes MF radar, (right) Variation of hourly meridional winds. Daily mean background winds are removed.

In Hoffmann et al. (2005), the underlying layering processes for the formation of multiple PMSE layers have been investigated by microphysical model simulations, where winds and temperatures were disturbed by a gravity wave with a vertical wavelength of $6 \mathrm{~km}$ and a period of $470 \mathrm{~min}$ (see Hoffmann et al., 2005, Fig. 3a-c). Summarizing their results, it has been shown that the gravity wave induced temperature variations have a strong influence on the resulting proxy distribution leading to multiple PMSE layer structures. According to the model calculations, the layering should be particularly pronounced in the presence of long period gravity waves with periods of about $6 \mathrm{~h}$, i.e., waves with a "correct" timing between ice particle nucleation, growth and sedimentation. Experimental tests of this approach were pre- sented in Hoffmann et al. (2005) using MF and VHF radar wind measurements during the PMSE observations. In a case study, ALWIN VHF radar wind measurements have been used, and indeed evidence for a long period gravity wave during the occurrence of a multiple PMSE layer was found. A climatological test was based on the kinetic energy of gravity waves of different scales derived from continuous MF radar winds during the main part of the PMSE period. It has been found, that the strongest correlation between MF Radar winds and daily occurrence rate of multiple PMSE layer occurs with the variances of meridional winds at $86 \mathrm{~km}$ for periods between 5 and $7 \mathrm{~h}$ (Hoffmann et al., 2005, Fig. 6), thus confirming the results of the model predictions. 


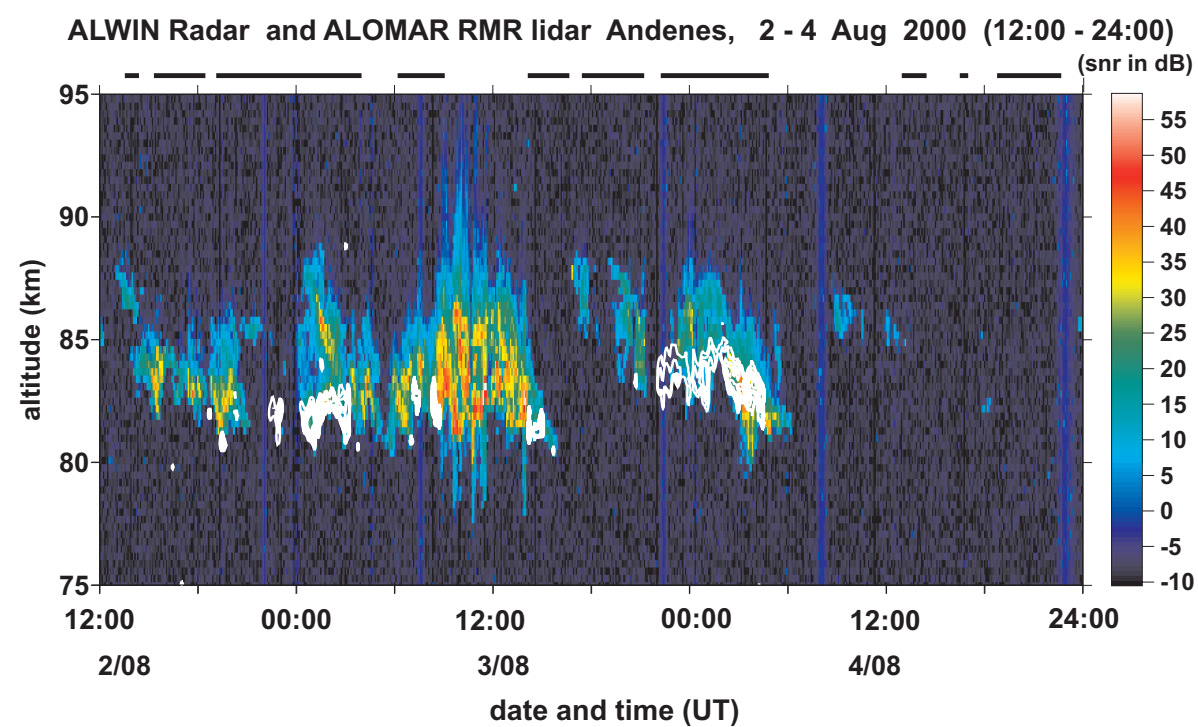

Fig. 7. Observational results: Simultaneous and common volume measurements of PMSE and NLC (white contour lines) during the period of enhanced semidiurnal tidal wave activity. The line at the top indicates when lidar observations have been carried out.
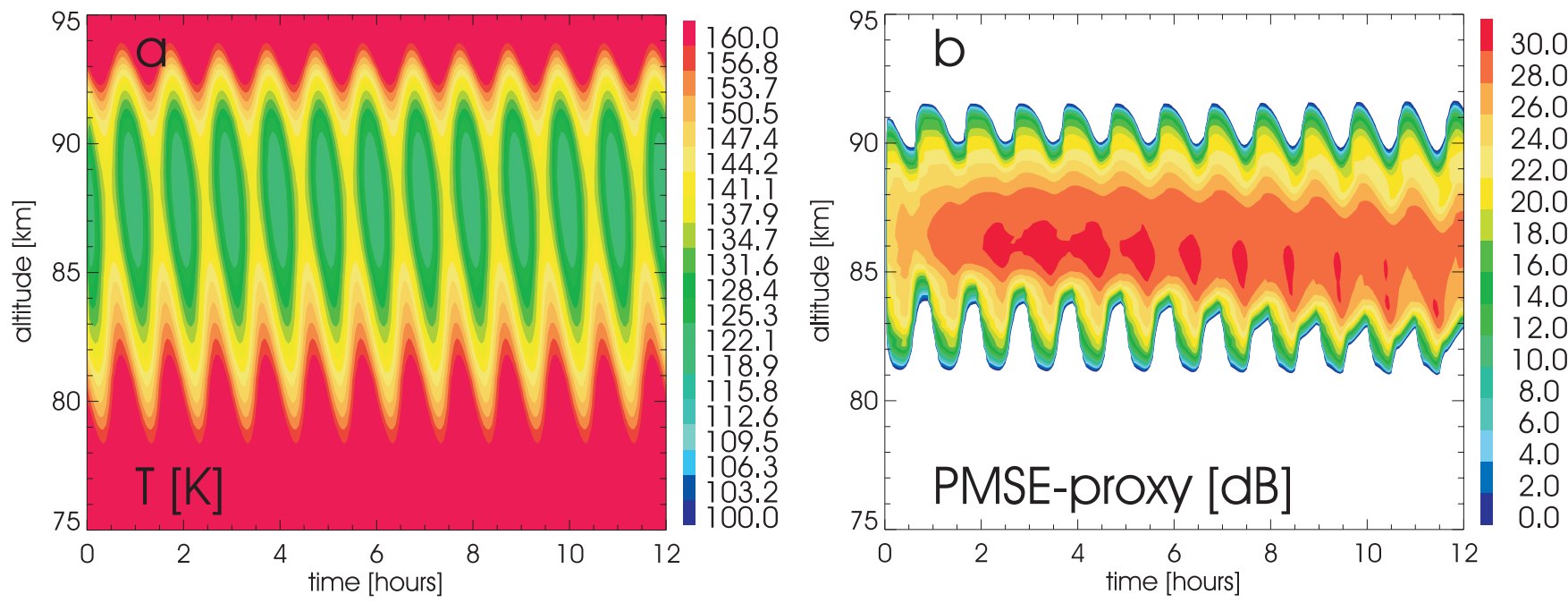

Fig. 8. Simulation of the influence of a short period gravity wave on PMSE: (a) temperature variations caused by a gravity wave with a period of $1 \mathrm{~h}$, (b) resulting PMSE strength.

\subsection{Influence of tidal waves on layering processes}

As mentioned in the introduction, the observations of NLC and PMSE show strong tidal variations (e.g. Fiedler et al., 2005; Morris et al., 2006), mainly determined by the semidiurnal component as the dominant mode at high latitudes. To investigate the influence of tidal waves on the formation of PMSE and NLC, microphysical model simulations have been carried out where the winds and temperatures have been disturbed by a single idealized wave with a period of $12 \mathrm{~h}$ and a vertical wavelength of $25 \mathrm{~km}$, which can be considered as realistic during PMSE observations (e.g. Carter and Balsley, 1982). Note also that the exact value of the vertical wavelength is not critical for these simulations as long as the vertical wavelength is large compared to a typical vertical extent of a PMSE layer, i.e., $\gg 10 \mathrm{~km}$. The temperature variations under the influence of this wave are shown in Fig. 5a.

The time-altitude development of the PMSE-proxy together with the lidar backscatter ratio at a wavelength of $532 \mathrm{~nm}$ is presented in Fig. 5b. The results clearly show that the wave induced temperature variations have a strong influence on the resulting reflectivity which is determined by a 


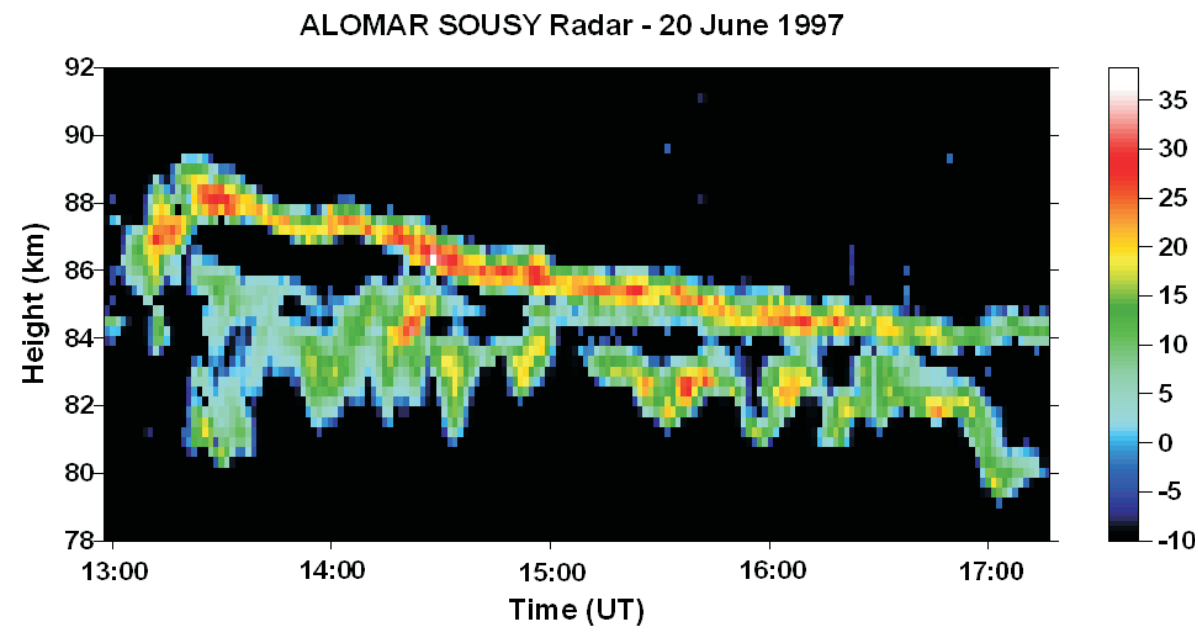

Fig. 9. Example of a short period variation of the lower edge of an observed PMSE.

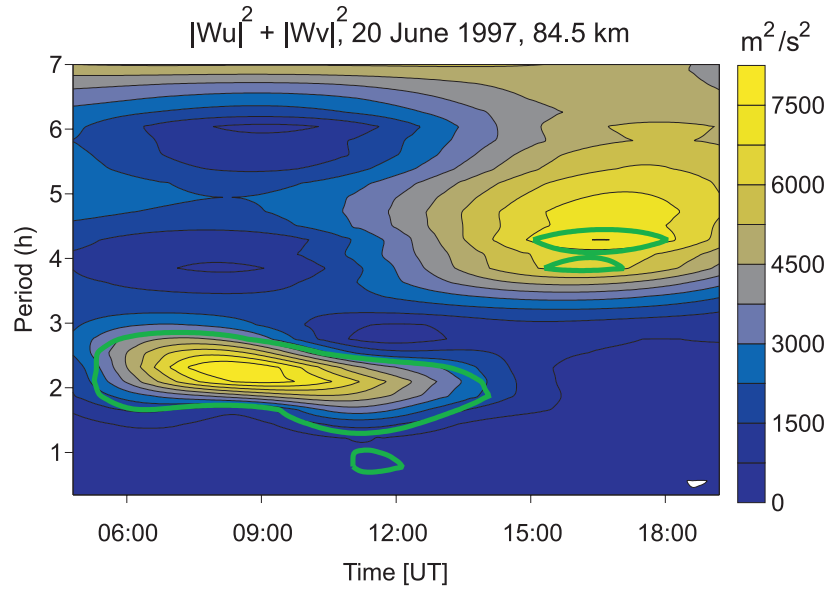

Fig. 10. Results of the Wavelet transform of horizontal winds from ALOMAR SOUSY radar measurements at an altitude of $84.5 \mathrm{~km}$. The bold green line outlines the region with $95 \%$ significance level.

$12 \mathrm{~h}$ variation and lead to strong PMSE structures, again with NLC at the lower edge of the PMSE.

To check this idealized situation with real data, we selected from the Andenes MF radar measurements a period with strong semidiurnal tides (SDT). Such periods start at high northern latitudes at the end of July and maximizes around the autumn equinox (e.g. Riggin et al., 2003). With the additional condition of simultaneous occurrence of PMSE and NLC we identified from our wind observations a period of enhanced SDT with amplitudes of about $30 \mathrm{~m} / \mathrm{s}$ from 3-4 August 2000 (Fig. 6, left panel). Note that the variation of hourly winds (Fig. 6, right panel) indicate a dominant influence of tidal waves so that the contribution of short period gravity waves can be neglected during this period. Simultaneous and common volume observation of PMSE with the ALWIN VHF-radar and of NLC with the ALOMAR RMRlidar show a clear tidal structure in the PMSE (Fig. 7) and strong NLC in the lower edge of the PMSE. The observations correspond very well to the modeled PMSE/NLC structure (Fig. 5b), clearly indicating that the timing between nucleation, growth and sedimentation of the ice particles on the one hand and the phase propagation on the other allows the formation of the observed structure with relatively large ice particles leading to the large volume backscatter ratios derived from the observed NLC structures. Interestingly, the SDT does not lead to multiple PMSE layers like in the case of gravity waves with periods in the $5-7 \mathrm{~h}$ range. The reason for this can be found in the very different vertical wavelengths, a) of the SDT, here with values of $25 \mathrm{~km}$, but large compared to a typical vertical extent of a PMSE layer of about $\gg 10 \mathrm{~km}$, and b) of the gravity waves in the 5-7 h range with vertical wavelengths in the order of about $6 \mathrm{~km}$ and leading to the enhanced formation of multiple PMSE layers.

\subsection{Influence of short period waves on PMSE and NLC}

To investigate the influence of short period gravity waves on PMSE and NLC, a simulation was performed where the winds and temperatures were disturbed by an idealized wave with a period of $1 \mathrm{~h}$ and a vertical wavelength of $20 \mathrm{~km}$. The resulting temperature variations are shown in Fig. 8a. Here, the wave prohibits the growth of large ice particles such that NLC formation does not occur (Fig. 8b) (see also Rapp et al., 2002, for more details of the relevant microphysical processes). Instead, there is a pronounced up- and downward motion of the PMSE. Such up- and downward motions of the lower or upper edge of the PMSE can regularly be found in observations (Fig. 9) and are related to observed 

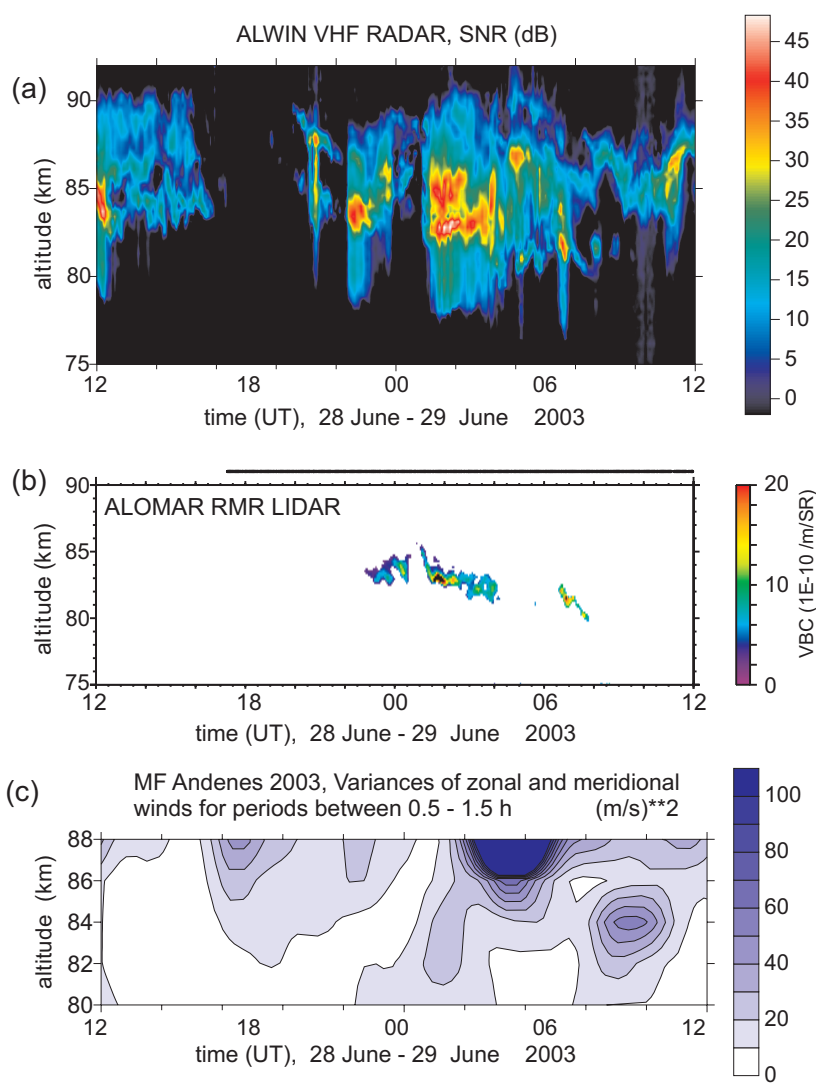

Fig. 11. Observations at Andenes from 28-29 June 2003: (a) PMSE observation with the ALWIN-VHF-Radar. (b) Signatures of NLC derived from simultaneous observations with the ALOMAR-RMRlidar, represented by their volume backscatter coefficients. The line at the top indicates when lidar observations have been carried out. (c) Wind variances of gravity waves with period between $2-4 \mathrm{~h}$ derived from the Andenes MF radar.

characteristics of short term gravity waves. The presence of short period gravity waves has been identified by a Morletwavelet transform (e.g. Serafimovich et al., 2005) of zonal and meridional winds at an altitude of $84.5 \mathrm{~km}$ (Fig. 10) derived from the VHF radar measurements during the presence of PMSE on the same day.

To investigate the influence of short period gravity waves on both PMSE and NLC, we selected a period with long lasting simultaneous and common volume PMSE and NLC observations and enhanced variances of short period wind fluctuations identified from our MF radar observations from 28 June to 1 July 2003. Note that this period belongs to the core period of PMSE and NLC observations. PMSE observations have been characterized by their signal-to-noise ratios (Figs. 11a and 12a), whereas signatures of NLC (Figs. 11b and $12 \mathrm{~b}$ ) are represented by their volume backscatter coefficients (Fiedler et al., 2003). The lines at the top of Figs. 11b and $12 \mathrm{~b}$ indicate when lidar observations have been carried out.
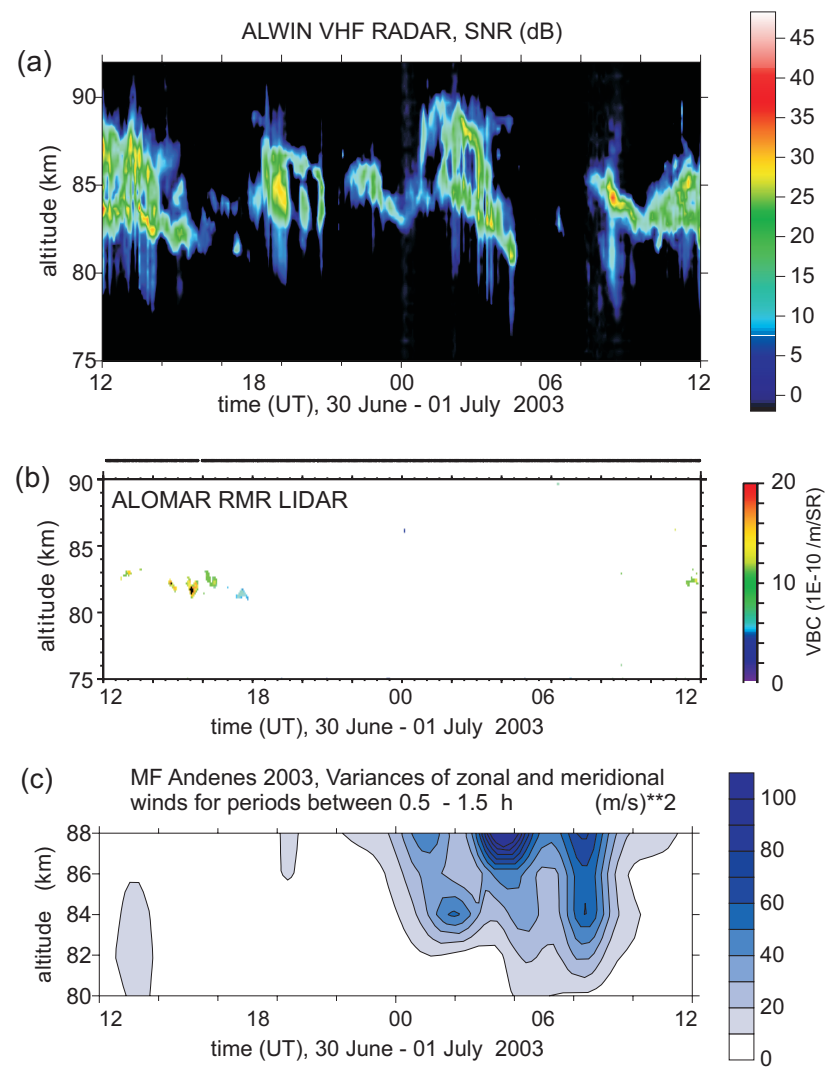

Fig. 12. As Fig. 11, but from 30 June-1 July 2003.

The gravity wave activity per mass unit is derived from the MF radar winds using a summarized scale-averaged wavelet power. This method is very efficient (e.g. Hoffmann et al., 2006, 2007) and comparable to the variances estimated after a classical Butterworth band-pass filtering. To improve the resolution, the data have been averaged only over $20 \mathrm{~min}$ in the altitude range between $80-88 \mathrm{~km}$ instead of the regularly used hourly averaged wind values.

The wind variances have been estimated for periods between $0.5-1.5 \mathrm{~h}$ and are presented in the lower panels of Figs. 11 and 12. At altitudes of $\sim 84-86 \mathrm{~km}$, periods of enhanced activity of these waves have been derived on 29 June, $\sim$ 10:00 UT, and 1 July, 00:00-08:00 UT. Note that during the selected period the SDT shows maximal amplitudes of only $10-12 \mathrm{~m} / \mathrm{s}$ (Fig. 13), thus indicating a reduced influence of tidal waves in comparison to the case study with enhanced SDT activity from 3-4 August 2000 (Fig. 6, left panel).

The results of the long lasting NLC observations show a relatively low occurrence of NLC on 29 June, the absence of NLC on 1 July and only weak PMSE during or after the periods of enhanced activity of short period gravity waves, thus confirming the predictions of the microphysical model simulation (Fig. 8). This means that the wave will cause only an up- and downward motion of the PMSE layer and suppress 

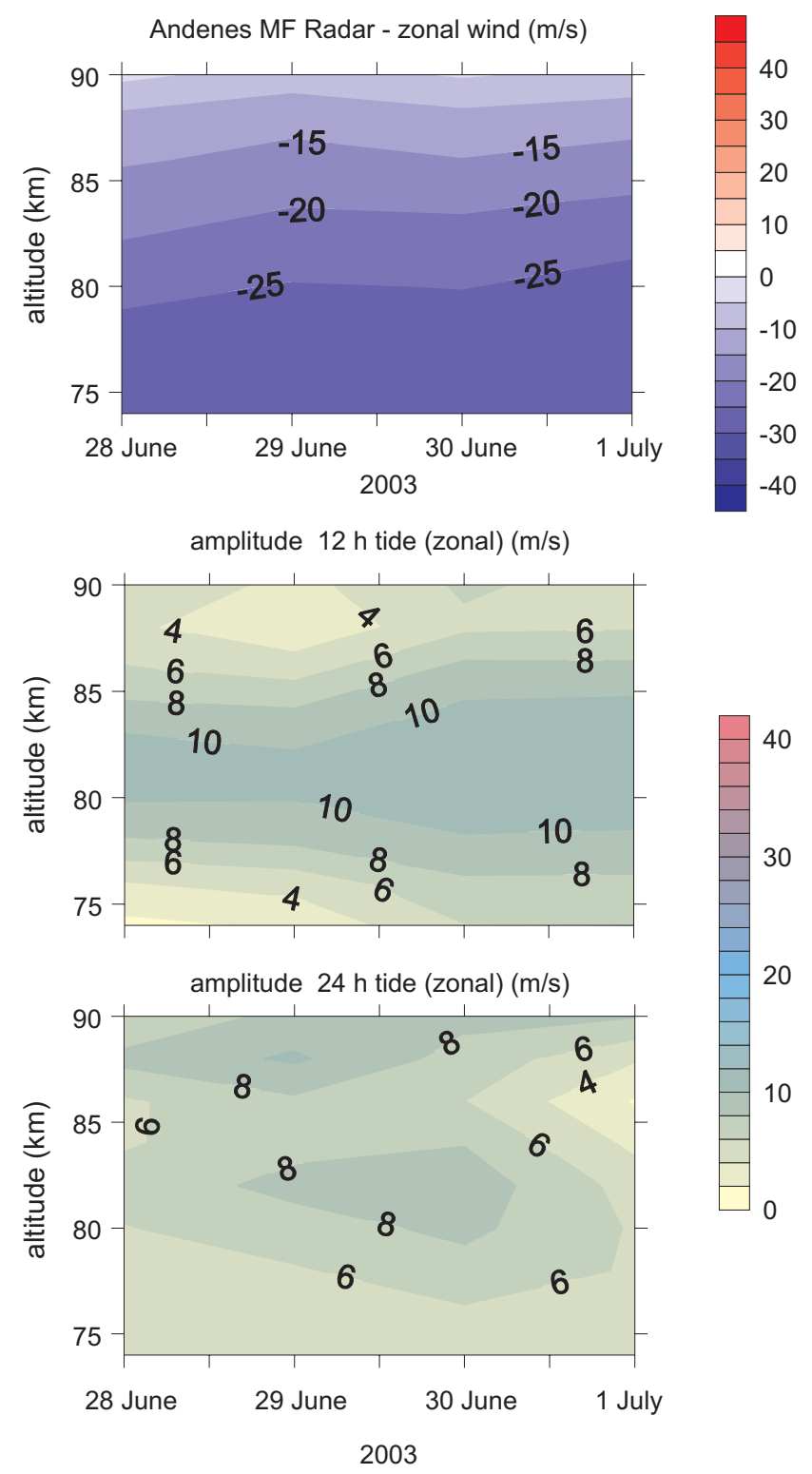

Fig. 13. Mean zonal wind and amplitudes of their semidiurnal and diurnal variation derived from Andenes MF radar observations from 28 June-1 July 2003.

the mesospheric ice formation due to the larger time constant necessary for the ice layer formation in comparison to the wave period.

\section{Conclusions}

In this paper, we have investigated the influence of short and long period gravity waves as well as of tidal waves on layering processes in the polar summer mesopause region leading to NLC and PMSE. For these purposes, microphysical model simulations of the generation and growth of mesospheric charged particles have been carried out to consider the impact of idealized wave disturbances with different scales on the microphysics of ice particles. The results of these simulations have been tested using simultaneous observations of winds, PMSE, and NLC.

The observations of PMSE at Andenes $\left(69^{\circ} \mathrm{N}, 16^{\circ} \mathrm{E}\right)$, Norway, show that the radar echoes occur with a rate of about $50 \%$ in the form of two or more distinct layers. In the case of multiple PMSE layers, statistical analysis shows that the lower layer occurs at a mean height of $\sim 83.4 \mathrm{~km}$, which is almost identical to the mean height of NLC derived from observation with the ALOMAR Rayleigh/Mie/Raman lidar at the same site.

The influence of gravity waves on the formation of multiple PMSE layers has been investigated in detail by Hoffmann et al. (2005) using microphysical model simulations and experimental validations. Summarizing their results, simulations under the influence of gravity waves with periods of about $6 \mathrm{~h}$ predict an enhanced formation of multiple PMSE layer structures, where the lower layer is a consequence of the occurrence of the largest particles at the bottom of the ice cloud. This explains the coincidence of the lowermost PMSE layers and NLC, experimentally confirmed here by the histograms of the centroid heights of PMSE and NLC and by their mean diurnal variations.

Microphysical model simulations were also performed under the influence of tides and short period gravity waves. The wave parameter were chosen due to realistic and observed data. To test the obtained results experimentally, periods with simultaneous and common volume PMSE and NLC observations have been selected. During periods with enhanced amplitudes of the semidiurnal tide, the observed NLC and PMSE show pronounced tidal structures comparable to the results of corresponding microphysical simulations under the influence of an idealized semidiurnal tidal wave, clearly indicating that the timing between nucleation, growth and sedimentation of the ice particles on the one hand and the phase propagation on the other allows the formation of the observed structure with relatively large ice particles. Interestingly, the SDT does not lead to several PMSE layers in the vertical profile. This can be explained by the difference between the vertical wavelength of the SDT which is larger than the vertical extent of the PMSE layer and of the vertical wavelength of about $6 \mathrm{~km}$ for the gravity waves with periods between $5-7 \mathrm{~h}$ leading to the enhanced formation of multiple PMSE layers.

Microphysical simulations under the influence of short period gravity waves predict that such waves only cause pronounced up- and downward motions of the PMSE, but prohibits the growth of large ice particles and hence the formation of NLC due to the larger time constant necessary for the ice layer formation in comparison to the wave period. These results have been confirmed in case studies during long lasting simultaneous measurements of PMSE and NLC, where during and after the periods of enhanced activity of gravity 
waves with periods of about $1 \mathrm{~h}$ a markedly reduced occurrence of NLC and only weak PMSE have been observed.

The main aim of our study was to understand the mechanisms by which single idealized waves can influence layering processes in the polar summer mesopause region leading to NLC and PMSE. However, to explain the high variability of our PMSE and NLC observations, we have to take into account that the dynamics in that region is determined by a superposition of atmospheric waves with different frequencies, amplitudes and vertical wavelengths. For the future, the effect of such superimposed waves should be considered in more depth, both experimentally and using suitable microphysical models.

Acknowledgements. We are indebted to the staff of the IAP and the Andoya rocket range for their permanent support. This work has been supported by an "Access to the ALOMAR research infrastructure" project CT-2003-506208 of the European Community. The authors would like to thank both reviewers for valuable comments on the first draft.

Topical Editor U.-P. Hoppe thanks M. Jarvis and another anonymous referee for their help in evaluating this paper.

\section{References}

Barabash, V., Chilson, P., Kirkwood, S., K., and Stebel, A. R.: Investigations of the possible relationship between PMSE and tides using a VHF MST radar, Geophys. Res. Lett., 25, 3297-3300, doi:10.1029/98GL02557, 1998.

Baumgarten, G. and Fiedler, J.: Vertical structure of particle properties and water content in noctilucent clouds, Geophys. Res. Lett., 35, L10811, doi:10.1029/2007GL033084, 2008.

Bremer, J., Hoffmann, P., Latteck, R., and Singer, W.: Seasonal and long-term variations of PMSE from VHF radar observations at Andenes, Norway, J. Geophys. Res., 108(D8), 8438, doi:10.1029/2002JD002369, 2003.

Carter, D. A. and Balsley, B. B.: The summer wind field between 80 and $93 \mathrm{~km}$ observed by the MST radar at Poker Flat, Alaska (65ํ N), J. Atmos. Sci., 39, 2905-2915, 1982.

Czechowsky, P., Rüster, R., and Schmidt, G.: Variations of mesospheric structures in different seasons, Geophys. Res. Lett., 6, 459-462, 1979

Ecklund, W. L. and Balsley, B. B.: Long-term observations of the Arctic mesosphere with the MST radar at Poker Flat, Alaska, J. Geophys. Res., 86, 7775-7780, 1981.

Fiedler, J., Baumgarten, G., and von Cossart, G.: Noctilucent Clouds above ALOMAR between 1997 and 2001: Occurence and Properties, J. Geophys. Res., 108, 8453, doi:10.1029/ 2002JD002419, 2003.

Fiedler, J., Baumgarten, G., and von Cossart, G.: Mean diurnal variations of noctilucent clouds during 7 years of lidar observations at ALOMAR, Ann. Geophys., 23, 1175-1181, 2005, http://www.ann-geophys.net/23/1175/2005/.

Hall, C. M. and Röttger, J.: Initial observations of Polar Mesospheric Summer Echoes using the EISCAT Svalbard radar, Geophys. Res. Lett., 28, 131-134, 2001.
Hansen, G., Servazi, M., and von Zahn, U.: First detection of a noctilucent clouds by lidar, Geophys. Res. Lett., 16, 1445-1448, 1989.

Hill, R. J., Gibson-Wilde, D. E., Werne, J. A., and Fritts, D. C.: Turbulence-induced fluctuations in ionization and application to PMSE, Earth Plan. Space, 51, 499-513, 1999.

Hoffmann, P., Singer, W., and Bremer, J.: Mean seasonal and diurnal variations of PMSE and winds from 4 years of radar observations at ALOMAR, Geophys. Res. Lett., 26, 1525-1528, 1999.

Hoffmann, P., Rapp, M., Serafimovich, A., and Latteck, R.: On the occurrence and formation of multiple layers of polar mesosphere summer echoes, Geophys. Res. Lett., 32, L05812, doi:10.1029/2004GL021409, 2005.

Hoffmann, P., Serafimovich, A., Peters, D., Dalin, P., Goldberg, R., and Latteck, R.: Inertia gravity waves in the upper troposphere during the MaCWAVE winter campaign, Part I: Observations with collocated radars, Ann. Geophys., 24, 2851-2862, 2006, http://www.ann-geophys.net/24/2851/2006/.

Hoffmann, P., Singer, W., Keuer, D., Hocking, W. K., Kunze, M., and Murayama, Y.: Latitudinal und longitudinal variability of mesospheric winds and temperatures during stratospheric warming events, J. Atmos. Solar Terr. Phys., 69, 2355-2366, 2007.

Jarvis, M. J., Clilverd, M. A., Rose, M. C., and Rodwell, S.: Polar mesosphere summer echoes (PMSE) at Halley $\left(76^{\circ} \mathrm{S}, 27^{\circ} \mathrm{W}\right)$, Antarctica, Geophys. Res. Lett., 32, L06816, doi:10.1029/2004GL021804, 2005

Kirkwood, S., Barabash, V., Chilson, P., Rechou, A., and Stebel, K.: The 1999 PMSE season - its relation to wind, temperature, and water vapour, Geophys. Res. Lett., 25, 1867-1870, 1998.

Kirkwood, S., Wolf, I., Nilsson, H., Dalin, P., Mikhaylova, D., and Belova, E.: Polar mesosphere summer echoes at Wasa, Antarctica $\left(73^{\circ} \mathrm{S}\right)$ : First observations and comparison with $68^{\circ} \mathrm{N}$, Geophys. Res. Lett., 34, L15803, doi:10.1029/2007GL030516, 2007.

Klostermeyer, J.: A height- and time-dependent model of polar mesosphere summer echoes, J. Geophys. Res., 102, 6715-6727, 1997.

Latteck, R., Singer, W., Morris, R. J., Holdsworth, D. A., and Murphy, D. J.: Observation of polar mesosphere summer echoes with calibrated VHF radars at $69^{\circ}$ in the Northern and Southern hemispheres, Geophys. Res. Lett., 34, L14805, doi:10.1029/2007GL030032, 2007.

Morris, R. J., Murphy, D. J., Reid, I. M., Holdsworth, D. A., and Vincent, R. A.: First polar mesosphere summer echoes observed at Davis, Antarctica, (68.2 $\left.{ }^{\circ} \mathrm{S}\right)$, Geophys. Res. Lett., 31, L16111, doi:10.1029/2004GL020352, 2004.

Morris, R. J., Murphy, D. J., Vincent, R. A., Holdsworth, D. A., Klekociuk, A. R., and Reid, I. M.: Characteristics of the wind, temperature and PMSE field above Davis, Antarctica, J. Atmos. Solar Terr. Phys., 68, 418-435, doi:10.1016/j.jastp.2005.04.011, 2006.

Morris, R. J., Murphy, D. J., Klekociuk, A. R., and Holdsworth, D. A.: First complete season of PMSE observations above Davis, Antarctica, and their relations to winds and temperatures, Geophys. Res. Lett., 34, L05805, doi:10.1029/2006GL028641, 2007.

Rapp, M. and Lübken, F.-J.: Polar mesosphere summer echoes (PMSE): Review of observations and current understanding, Atmos. Chem. Phys., 4, 2601-2633, 2004, http://www.atmos-chem-phys.net/4/2601/2004/.

Rapp, M., Lübken, F.-J., Müllemann, A., Thomas, G. E., and 
Jensen, E. J.: Small Scale Temperature Variations in the Vicinity of NLC: Experimental and Model Results, J. Geophys. Res., 107(D19), 4392, doi:10.1029/2001JD001241, 2002.

Rapp, M., Lübken, F.-J., Hoffmann, P., Latteck, R., Baumgarten, G., and Blix, T.: PMSE dependence on aerosol charge number density and aerosol size, J. Geophys. Res., 108, 8441, doi:10. 1029/2002JD002650, 2003.

Riggin, D., Meyer, C., Fritts, D., Jarvis, M., Murayama, Y., Singer, W., Vincent, R., and Murphy, D.: MF radar observations of seasonal variability of semidiurnal motions in the mesosphere at high northern and southern latitudes, J. Atmos. Solar Terr. Phys., 65, 483-493, 2003.

Röttger, J.: The dynamics of stratospheric and mesospheric fine structure investigated with an MST VHF Radar, in: Middle Atmosphere Program, Handbook for MAP, edited by: Avery, S. K., vol. 2, pp. 341-349, SCOSTEP Secretariat, University of Illinois, 1981.

Röttger, J.: Middle atmosphere and lower thermossphere processes at high latitudes studied with the EISCAT radars, J. Atmos. Terr. Phys., 56, 1173-1195, 1994.

Röttger, J.: About multiple layering and aspect sensitivity of polar mesosphere summer echoes, in: Proceedings of the Tenth International Workshop on Technical and Scientific Aspects of MST radar, edited by Chau, J., Lau, J., and Röttger, J., pp. 54-57, Universidad de Piura, Peru, 2003.

Röttger, J., LaHoz, C., Kelley, M. C., Hoppe, U.-P., and Hall, C.: The structure and dynamics of polar mesosphere summer echoes observed with the EISCAT $224 \mathrm{MHz}$ radar, Geophys. Res. Lett., 15, 1353-1356, 1988.

Serafimovich, A., Hoffmann, P., Peters, D., and Lehmann, V.: Investigation of inertia-gravity waves in the upper troposphere/lower stratosphere over Northern Germany observed with collocated VHF/UHF radars, Atmos. Chem. Phys., 5, 295-310, 2005, http://www.atmos-chem-phys.net/5/295/2005/.
Singer, W., Keuer, D., and Eriksen, W.: The ALOMAR MF radar: Technical design and first results, in: Proceedings of the 13th ESA Symposium on European Rocket and Balloon Programmes and Related Research, Oeland, Sweden (ESA SP-397), edited by: Kaldeich-Schürmann, B., pp. 101-103, ESA Publications Division, 1997.

Singer, W., Latteck, R., Hoffmann, P., Williams, B. P., Fritts, D. C., Murayama, Y., and Sakanoi, K.: Tides near the Arctic summer mesopause during the MaCWAVE/MIDAS summer program, Geophys. Res. Lett., 32, L07S90, doi:10.1029/2004GL021607, 2005.

Torrence, C. and Compo, G. P.: A practical guide to wavelet analysis, B. Am. Meteorol. Soc., 79, 61-78, 1998.

von Zahn, U. and Bremer, J.: Simultaneous and common-volume observations of noctilucent clouds and polar mesosphere summer echoes, Geophys. Res. Lett., 26, 1521-1524, 1999.

von Zahn, U., von Cossart, G., Fiedler, J., and Rees, D.: Tidal variations of noctilucent clouds measured at $69^{\circ} \mathrm{N}$ latitude by groundbased lidar, Geophys. Res. Lett., 25, 1289-1292, doi: 10.1029/98GL00546, 1998.

von Zahn, U., von Cossart, G., Fiedler, J., Fricke, K. H., Nelke, G., Baumgarten, G., Rees, D., Hauchecorne, A., and Adolfsen, K.: The ALOMAR Rayleigh/Mie/Raman lidar: Objectives, configuration, and performance, Ann. Geophys., 18, 815-833, 2000, http://www.ann-geophys.net/18/815/2000/.

Williams, P. J. S., Jones, G. O. L., Palmer, J. R., and Rishbeth, H.: The association of polar mesosphere summer echo layers with tidal modes, Ann. Geophys., 13, 454-457, 1995, http://www.ann-geophys.net/13/454/1995/. 